\title{
Wintermärchen im Palmengarten
}

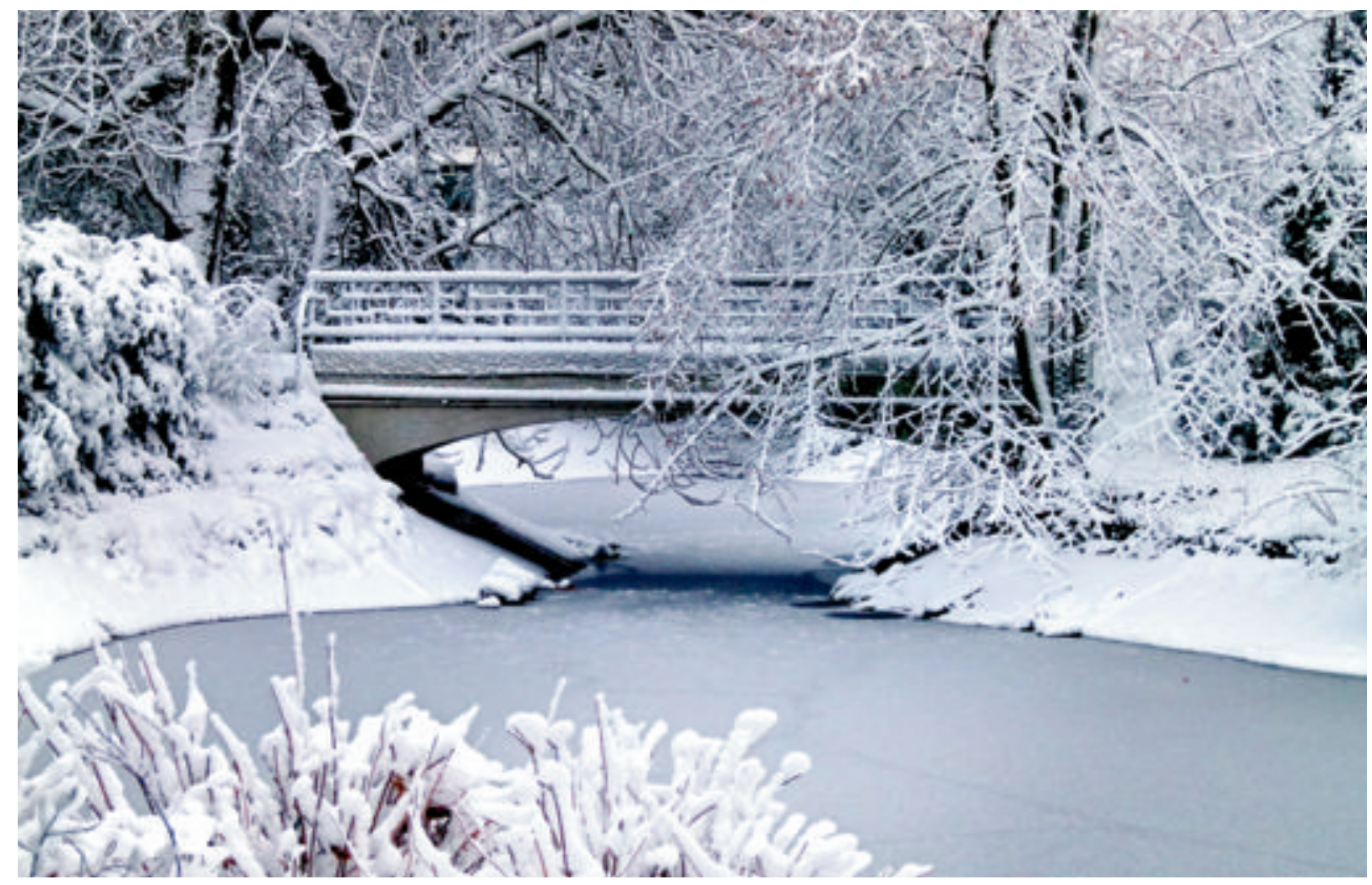

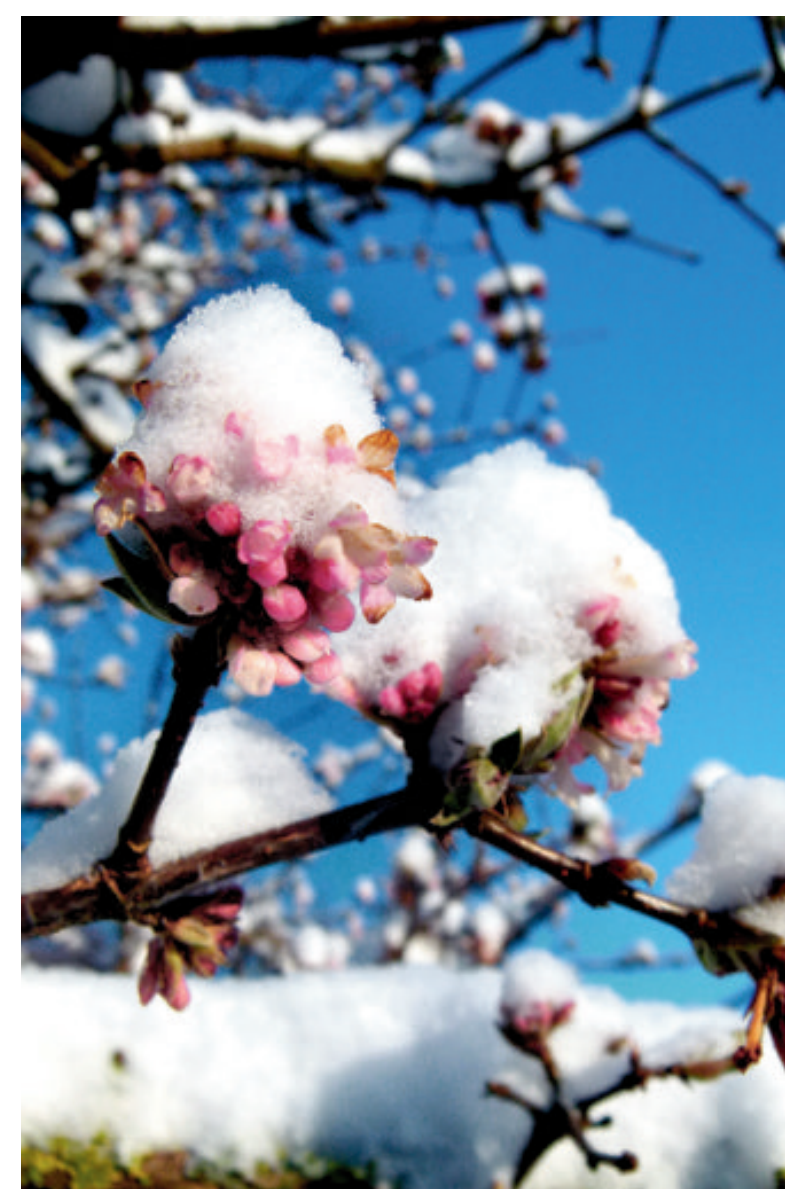

Abb. 1 (oben): Brücke über den Kleinen Weiher.

Abb. 2 (unten): Winter-Schneeball mit Schneehäubchen.

Abb. 3 (S. 165 oben): Unter der Schneelast verneigt sich der Bambus.

Abb. 4 (S. 165 unten links): Subantarktishaus mit Spiegeleffekten.

Abb. 5 (S. 165 unten rechts): Eingeeiste CotoneasterFrüchte. 

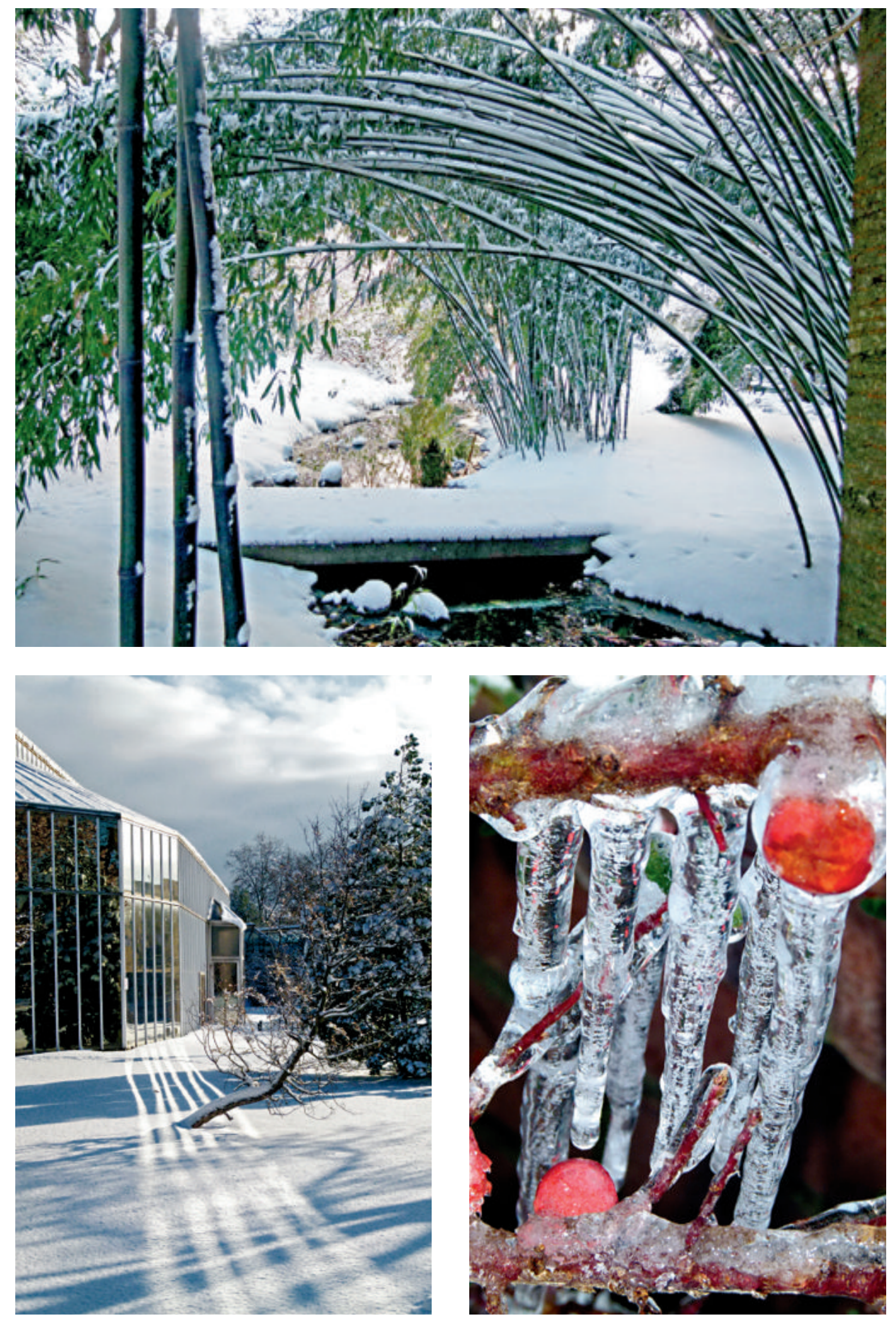

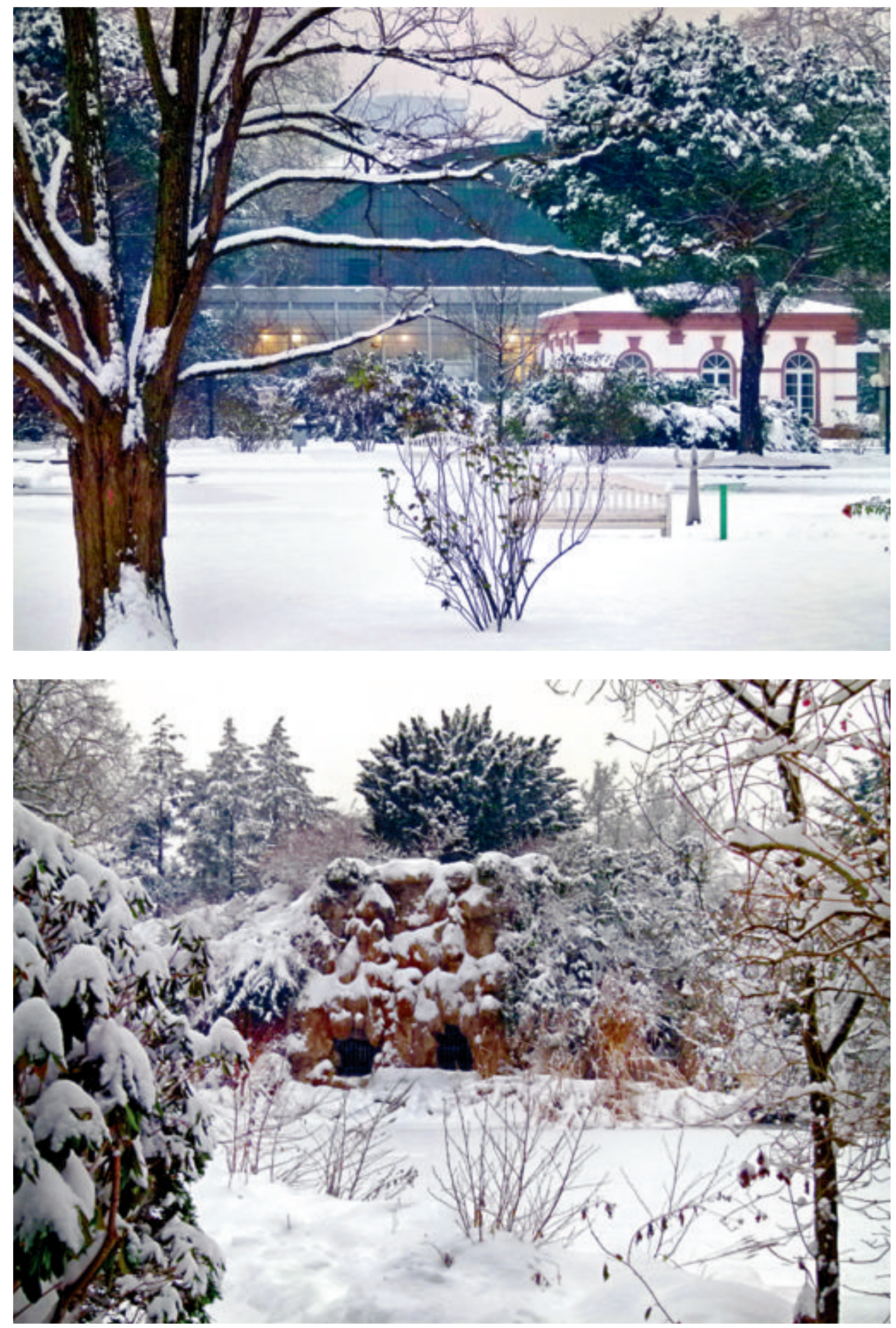


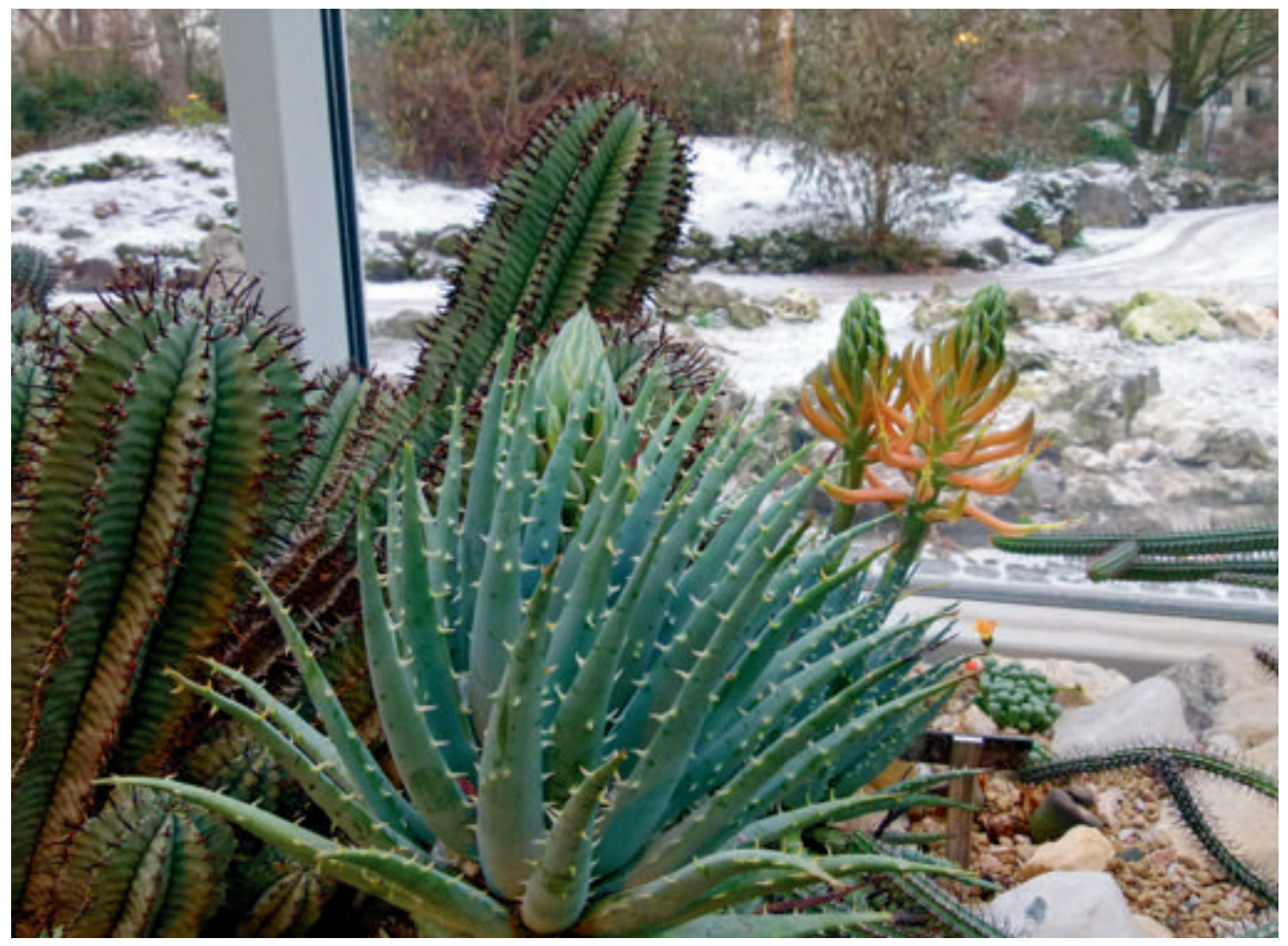

Abb. 6 (S. 166 oben): Blick auf Haus Rosenbrunn und das Palmenhaus mit den Galerien.

Abb. 7 (S. 166 unten): Blick über den Weiher auf die Grotte.

Abb. 8 (oben): Kontrastprogramm: Wärme in der botanischen Sammlung und Schnee im Freiland.

Abb. 9 (unten): Alte Fruchtstände des Brandkrautes mit Schneemützen.

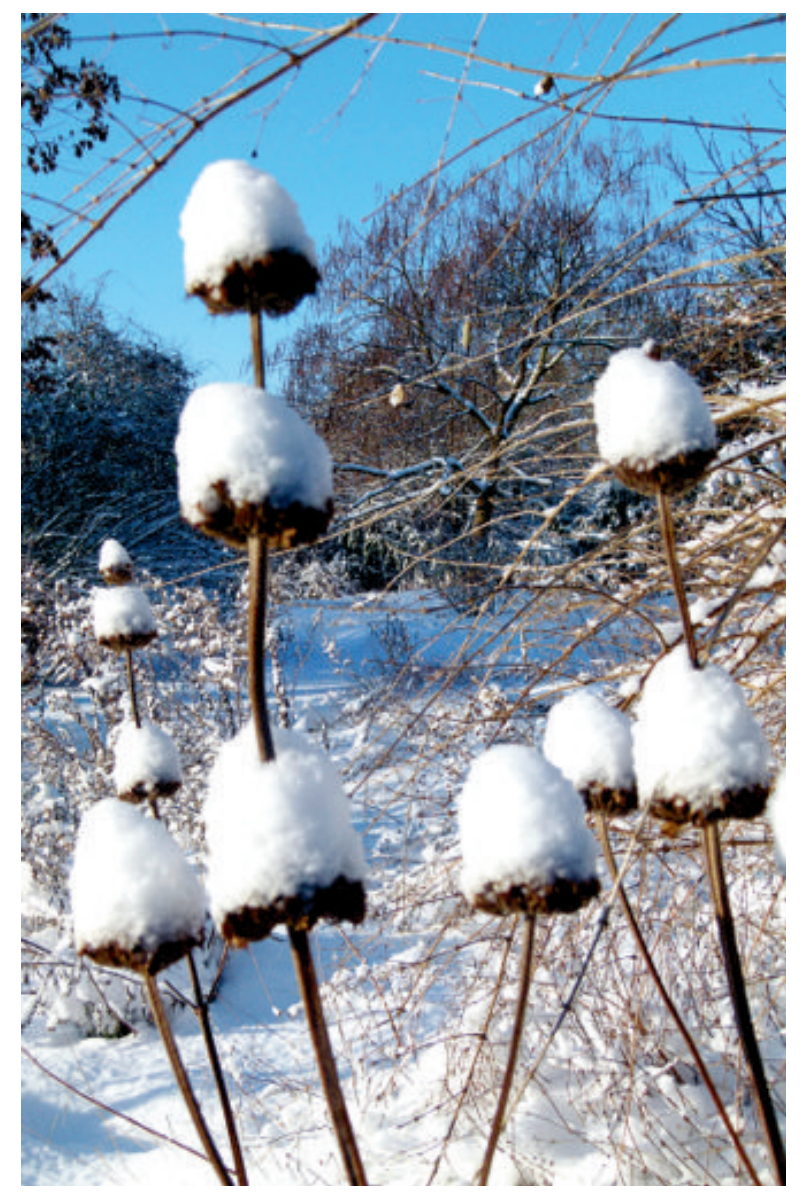

